DE

M E D I C I N A

T R O P I C A L

$\mathrm{DE}$

SÃO PAULO

JOURNAL OF THE SÃO PAULO INSTITUTE OF TROPICAL MEDICINE

'Superintendência de Vigilância em Saúde do Amapá, Laboratório de Vetores, Macapá, Amapá, Brazil

2Superintendência de Vigilância em Saúde do Amapá, Laboratório de Virologia, Macapá, Amapá, Brazil

${ }^{3}$ Polícia Técnico Científica do Amapá, Departamento de Laboratórios Forenses, Macapá, Amapá, Brazil

${ }^{4}$ Universidade Federal do Amapá, Laboratório de Arthropoda, Macapá, Amapá, Brazil

5Universidade de São Paulo, Escola Politécnica, Programa de Pós-Graduação em Engenharia Elétrica, São Paulo, São Paulo, Brazil

'Universidade de São Paulo, Instituto de Medicina Tropical de São Paulo, Laboratório de Virologia, São Paulo, São Paulo, Brazil

Correspondence to: Fred Júlio Costa Monteiro

Superintendência de Vigilância em Saúde do Amapá, Laboratório de Vetores, Rua Tancredo Neves, 1118, CEP 68908-530, Macapá, AP, Brazil

E-mail: fredjulio@gmail.com

Received: 2 September 2019

Accepted: 13 January 2020

\section{Prevalence of dengue, Zika and chikungunya viruses in Aedes (Stegomyia) aegypti (Diptera: Culicidae) in a medium-sized city, Amazon, Brazil}

Fred Júlio Costa Monteiro ${ }^{\circledR 1}$, Fábio Rodrigo Paixão Mourão ${ }^{\circledR 1}$, Edicelha Soares D’Athaide Ribeiro ${ }^{\circledR 2}$, Marlisson Octávio da Silva Rêgo ${ }^{\circledR 2}$, Pablo Abdon da Costa Frances ${ }^{\circledR 3}$, Raimundo Nonato Picanço Souto ${ }^{\circledR} 4$, Marlucia dos Santos Façanha ${ }^{\circledR}$, Roozbeh Tahmasebi ${ }^{\circledR 5}$, Antônio Charlys da Costa ${ }^{\circledR 6}$

\section{ABSTRACT}

Aedes aegypti is associated with epidemic diseases in Brazil, such as urban yellow fever, dengue, and more recently, chikungunya and Zika viruses infections. More information about $A$ e. aegypti infestation is fundamental to virological surveillance in order to ensure the effectiveness of control measures in use. Thus, the present study aims to identify and compare infestation and infectivity of Ae. aegypti females in Macapa city, Amapa State (Amazon region), Brazil, between the epidemiological weeks 2017/02 and 2018/20. A total number of 303 Ae. aegypti females were collected at 21 fixed collection points, 171 at the 10 collection points in the Marabaixo neighborhood and 132 at the 11 collection points in the Central neighborhood. Among the collected samples, only two were positive for dengue virus, with a $2.08 \%$ (2/96 pools) infectivity rate for Marabaixo. The difference between the medians of Ae. aegypti females captured in Central and Marabaixo sites was not statistically significant. The findings indicate similar mosquito infestation levels between the neighborhoods, and a low-level of mosquito infectivity, although dengue virus was found only in Marabaixo. Virological surveillance of Ae. aegypti was important to identify sites of infection and determine possible routes of transmission to enable health surveillance teams to adopt preventive strategies where infected mosquitoes are present and act faster.

KEYWORDS: Arboviruses. Chikungunya. Dengue. Entomology. Infectivity. Infestation. Prevention. Surveillance in public health. Zika.

\section{INTRODUCTION}

Introduction of exotic vectors into new areas are associated with human epidemics throughout history ${ }^{1}$. In Brazil, Aedes (Stegomyia) aegypti (Diptera: Culicidae), a vector from Africa ${ }^{2}$, is a known transmitter of the viruses responsible for urban yellow fever, dengue and more recently chikungunya and Zika epidemics ${ }^{3}$.

The prevention and control of these arboviral diseases can be performed through immunobiologicals (vaccines against yellow fever ${ }^{4}$ and dengue ${ }^{5}$ ), by disruption of host-vector contact or vector control actions. Dengue, chikungunya and Zika prevention depends mainly on effective vector control measures, unlike yellow fever, for which vaccination is the most effective method ${ }^{6}$.

The main vector control action is to adopt measures to eliminate Ae. aegypti breeding sites. In addition, in places where probable cases of dengue, chikungunya and/or Zika infections are reported, measures to break the chain of transmission in 
the surrounding area with insecticide application must be considered (Ultra Low Volume) ${ }^{7}$.

Surveillance of diseases transmitted by Ae. aegypti is based on entomological indices and mandatory reporting of suspected/confirmed cases, which is often late ${ }^{8}$.

Macapa, the State capital of Amapa, has high infestation rates for Ae. aegypti in all the urban areas of the municipality. Summer monsoon brings rain from December to May, with the latter being the rainiest month with the highest recorded density of mosquitoes ${ }^{9}$. The city is 14 meters above sea level and has a humid tropical climate, with small temperature variations (average of $27^{\circ} \mathrm{C}$ ), an average annual relative humidity of $81 \%$ and an average rainfall of around 2,600 $\mathrm{mm}$. The driest period is from September to November (quarterly rainfall below $200 \mathrm{~mm}$ ) and the wettest period from March to May (quarterly rainfall higher than $1,000 \mathrm{~mm})^{10}$.

In places where there is a high infestation of Ae. aegypti, it is essential to establish a virological surveillance to determine more effective control measures. Thus, the present study aims to identify and compare the infestation and infectivity of Ae. aegypti females in two neighborhoods in the city of Macapa, between the epidemiological weeks 2017/02 and 2018/20.

\section{MATERIALS AND METHODS}

\section{Study area}

The research was conducted in the urban zone of the municipality of Macapa, the State capital of Amapa, located in the Brazilian Amazon, with an estimated population of 474,706 inhabitants in $2017^{11}$.

For this research, two neighborhoods were chosen: Central and Marabaixo, located in Central and Western Macapa, respectively (Figure 1). The former is the most urbanized neighborhood in the city, where the commercial and administrative areas are concentrated, and the largest coverage of water supply and sewage occurs. Houses are mostly built with both brick and stone masonry. Marabaixo is an unofficial neighborhood with deficient basic urban infrastructure, lacking coverage of water and sewage networks. The majority of the houses are made of brick and cement plaster, and there are also numerous wooden houses.
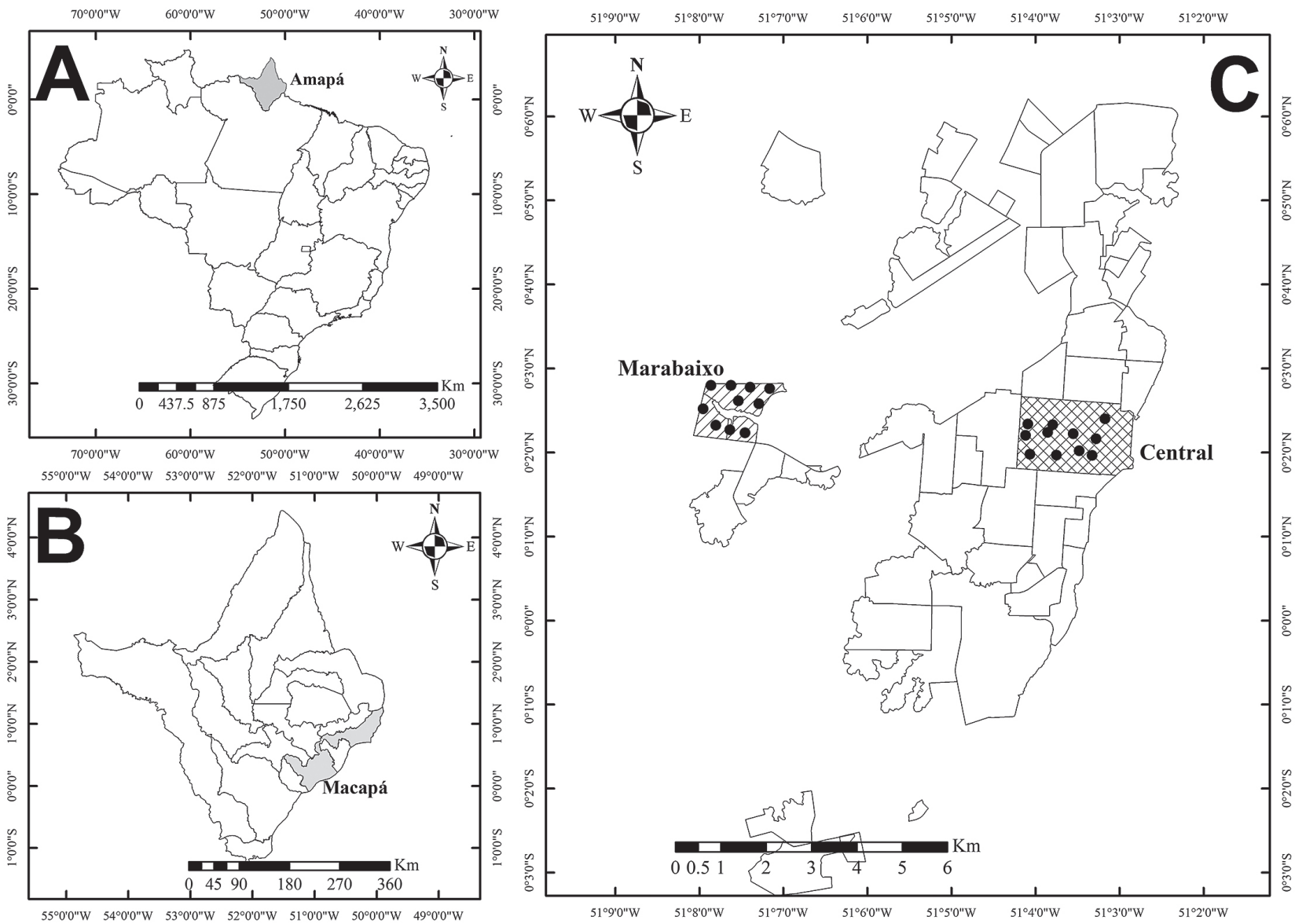

Figure 1 - A) Map of Brazil, highlighting the Amapa State in gray; B) Map of the Amapa State, showing the Macapa city in gray; C) Marabaixo and Central neighborhoods are highlighted in gray and the sites of collections are black dotted. 


\section{Sample collection}

Permanent collection points were established randomly, at approximately $400 \mathrm{~m}$ from each other, and they were georeferenced using the Universal Transverse Mercator (UTM), by means of the Garmin Oregon 550 GPS (Garmin International, Inc., Olathe, Kansas, USA).

Between the epidemiological weeks 2017/02 and $2018 / 20$, at each sampling point, mosquitoes were captured biweekly in peridomiciliary and intradomiciliary environments through electric aspirators ${ }^{12}$, Castro aspirators ${ }^{13}$ and insect collection nets.

Immediately afterwards, the captured insects were transported to the Vector Laboratory of the Epidemiological Surveillance Department of Amapa.

Using the key of Consoli and Oliveira ${ }^{14}, A e$. aegypti females were identified and classified as either non-blood fed females (without evidence of hematophagia) and blood fed females (females with blood in the abdomen). Following this classification, pools of up to five mosquitoes per tube, per epidemiological week, were prepared for each collection point. During the study, Ae. aegypti males and other trapped species of mosquitoes were discarded.

\section{Sample preparation and Quantitative Reverse Transcription Polymerase Chain Reaction (qRT-PCR) assay}

Initially, wings and legs were removed and discarded from collected mosquitoes. Samples were placed in $2.0 \mathrm{~mL}$ microcentrifuge tubes, then, they were stored at $-70{ }^{\circ} \mathrm{C}$ until analysis.

The pools were macerated in $1 \mathrm{~mL}$ phosphate saline (PBS), pH 7.4, through the Retsch Model MM400 Vibratory Mill (Retsch-Allee, Haan, Germany). Then, the samples were centrifuged for $10 \mathrm{~min}$ at $16,128 \mathrm{x}$ g. For nucleic acids extraction, approximately $300 \mu \mathrm{L}$ of the supernatant were pipetted and filtered $(0.22 \mu \mathrm{m})$ using the PureLink ${ }^{\mathrm{TM}}$ RNA/DNA Mini Kit (Invitrogen, Carlsbad, CA, USA) to obtain $50 \mu \mathrm{L}$ of purified nucleic acids, as recommended by the manufacturer.

Finally, the samples were aliquoted into qRT-PCR Fast plates along with the oligonucleotide sequences for dengue (DENV1, DENV2, DENV3 and DENV4), chikungunya and Zika viruses (Table 1), together with positive and negative controls for further interpretation of the results, as recommended by the manufacturer ${ }^{15-17}$.

\section{Statistical analysis}

For statistical analysis the software BioeEstat version 5.3 (Mamiraua Institute, Manaus, Brazil $)^{18}$ was used. The weeks during which collection in either site was not possible were discarded for statistical analysis.

Data were tested for Liliefors normality, which proved to be significant, and for this reason nonparametric tests were used.

Then, to compare the total of females captured between the studied neighborhoods, the Mann-Whitney test was used. To verify the difference between non-blood fed

Table 1 - Oligonucleotide sequences used for the detection of dengue, chikungunya and Zika viruses.

\begin{tabular}{llc}
\hline Virus & 5'-3' $^{\prime}$ Sequence & Reference \\
\hline DEN-1 Forward & CAAAAGGAAGTCGTGCAATA & Jonhson et al. ${ }^{15}$ \\
DEN-1 Reverse & CTGAGTGAATTCTCTCTACTGAACC & \\
DEN-1 Probe & CATGTGGTTGGGAGCACGC & \\
DEN-2 Forward & CAGGTTATGGCACTGTCACGAT & \\
DEN-2 Reverse & CCATCTGCAGCAACACCATCTC & \\
DEN-2 Probe & CTCTCCGAGAACAGGCCTCGACTTCAA & \\
DEN-3 Forward & GGACTGGACACACGCACTCA & \\
DEN-3 Reverse & CATGTCTCTACCTTCTCGACTTGTCT & \\
DEN-3 Probe & ACCTGGATGTCGGCTGAAGGAGCTTG & \\
DEN-4 Forward & TTGTCCTAATGATGCTGGTCG & \\
DEN-4 Reverse & TCCACCTGAGACTCCTTCCA & \\
DEN-4 Probe & TTCCTACTCCTACGCATCGCATTCCG & \\
\hline Chikungunya - Forward & CATCTGCACYCAAGTGTACCA & \\
Chikungunya - Reverse & GCGCATTTTGCCTTCGTAATG ${ }^{16}$ \\
Chikungunya - Probe & GCGGTGTACACTGCCTGTGACYGC & Waggoner et al. ${ }^{17}$ \\
\hline Zika - Forward & CAGCTGGCATCATGAAGAAYC & \\
Zika - Reverse & CACCTGTCCCATCTTTTTCTCC & \\
Zika - Probe & CYGTTGTGGATGGAATAGTGG & \\
\hline
\end{tabular}


Table 2 - Number of Ae. aegypti females collected in the survey and the mosquito pools by neighborhood.

\begin{tabular}{lcccccc}
\hline Mosquito collection sites & NBF & BF & Total & NBF Pool & EF Pool & Total Pool \\
\hline Central & 97 & 35 & 132 & 53 & 26 & 79 \\
Marabaixo & 107 & 64 & 171 & 61 & 35 & 96 \\
\hline Total & 204 & 99 & 303 & 104 & 61 & 175 \\
\hline
\end{tabular}

$\mathrm{NBF}=$ Ae. aegypti non-blood fed; $\mathrm{BF}=$ Ae. aegypti blood fed

females and blood fed females in each neighborhood, the same statistical method was applied. The results were considered significant when $\mathrm{p} \leq 0.05$.

\section{RESULTS}

A total of 303 Ae. aegypti females were collected, of which 132 were from the Central neighborhood (97 nonblood fed females and 35 blood fed females) and 171 from the Marabaixo neighborhood (107 non-blood fed females and 64 blood fed females), resulting in 175 pools, of which 79 were from the Central neighborhood (53 of non-blood fed females and 26 of blood fed females) and 96 from the Marabaixo neighborhood (61 of non-blood fed females and 35 of blood fed females) (Table 2).

There was no statistically significant difference between the medians of the total Ae. aegypti females captured in the Central (3) and the Marabaixo (3) neighborhoods (MannWhitney Test $\mathrm{U}=353.5 ; \mathrm{Z}(\mathrm{U})$ 0.1903; $\mathrm{p}=0.8491$ ).

In the Central neighborhood, there was a higher frequency of non-blood fed females (73.48\%) than blood fed females $(26.52 \%)$, with a statistically significant difference between the median number of non-blood fed females (2) and blood fed females (1) (Mann-Whitney $\mathrm{U}=243 ; \mathrm{Z}(\mathrm{U}) 2.1019 ; \mathrm{p}=0.0356$ ).

In the Marabaixo neighborhood, $62.57 \%$ of the captured females were non-blood fed, while $37.43 \%$ were blood fed ones, but the difference between the medians of non-blood fed (1) and blood fed (0) females was not statistically significant (Mann-Whitney U test $=305.5 \mathrm{Z}$ (U) 1.0207; $\mathrm{p}=0.3074)$.

Regarding the infectivity, the presence of dengue virus was only detected in two samples, both from the Marabaixo neighborhood, with a total infectivity of $2.08 \%$ (2/96), one from non-blood fed females (1/61 - DEN-1) and one from blood fed females (1/35 - DEN-4). For Zika and chikungunya viruses, no virus was detected in any sample.

According to the Epidemiological Surveillance Department of Amapa, during the research in Central neighborhood, 14 cases of dengue, five of chikungunya and none of Zika virus were confirmed. In Marabaixo neighborhood, 17 cases of dengue, three of chikungunya and one of Zika virus were confirmed.

\section{DISCUSSION}

The presence of vectors, the existence of cases of dengue, chikungunya and Zika viruses, and the population susceptibility are conditions that favor the occurrence of epidemics.

Ae. aegypti has a high predilection for human blood ${ }^{19}$. Thus, the high number of fed mosquitoes in both neighborhoods showed that vector control measurements have not prevented the host-vector contact.

The detection of a non-blood fed female pool highlights the possibility of dengue virus transmission, as the virus can be present in the insect salivary gland and can be transmitted during the blood meal. However, the presence of dengue virus in blood fed female does not distinguish whether the detected virus was present in the blood from the meal or from the mosquito salivary gland.

When virological surveillance in Ae. aegypti is performed close to the occurrence of confirmed cases of arboviruses, the percentage of positive females is higher, as demonstrated by Perez-Perez et al. ${ }^{8}$ who found in Medelín, Colombia, $35.42 \%$ of dengue virus infected female pools. Pérez-Castro et al. ${ }^{20}$ reported an infectivity of $62 \%$ of Ae. aegypti females in places where there were cases of dengue within $200 \mathrm{~m}$ of the collection point and 30 days before the collection date. In addition, in Aracaju city, the State capital of Sergipe, in Northeast Brazil, Costa-Silva et al..$^{21}$ found $10 \%$ (1/10 pools) of Ae. aegypti infected by chikungunya virus. In contrast, in Rio de Janeiro city, in Southeast Brazil, Ferreira-de-Brito et al. ${ }^{22}$ detected a low natural infectivity in Ae. aegypti with Zika virus of 1.15\% (3/198 pools).

The infectivity rates are lower when virological surveillance is independent from the reporting of positive cases, as is the case in the present study. This is corroborated by Baak-Baak et al. ${ }^{23}$, who found $1.2 \%$ (2/166) positivity for dengue virus in churches. Meanwhile, in Belo Horizonte, the State capital of Minas Gerais, Eiras et al. ${ }^{24}$ found $4.9 \%$ (4/82 pools) and $8.5 \%$ (7/82 pools) infectivity to dengue virus and Zika virus, respectively, at the university 
campus representing a higher risk of transmission for these populations.

Moreover, the possibility of transovarian transmission of dengue ${ }^{25}$, chikungunya ${ }^{26}$ and Zika ${ }^{27,28}$ in Ae. aegypti shows that a varied percentage of mosquitoes can be infected with these viruses. Thus, cases may occur without the need of a previous source of infection.

Dengue, chikungunya and Zika are underreported diseases ${ }^{29}$. Sometimes, these infections have subclinical manifestations. Additionally, some populations have less access to public health care, or, as is the case with Zika, laboratory examination is often required only for groups considered at higher risk, such as pregnant women.

In Brazil, Ae. aegypti entomological surveillance is based on the monitoring of immature forms (Larval Index Rapid Assay for Ae. aegypti - LIRA) as recommended by the Brazilian Health Ministry. Thus, according to the prevalence of Ae. aegypti immature forms, each stratum (area between 2,000 to 12,000 properties) receives a risk rating: low $(\leq 0.9 \%)$, medium $(1 \%-3.9 \%)$ or high $(\geq 4 \%)^{30}$. This method depends on the accuracy of the inspector to collect immature forms. In addition, Macapa city does not have specialized staff equipped with stairs to inspect elevated deposits such as water boxes and gutters.

The epidemiological surveillance of dengue, chikungunya and Zika is performed by the follow-up of reported cases, thus helping the health surveillance teams to find sites for implementing vector control actions aimed at interrupting the transmission of the disease ${ }^{7}$.

In general, surveillance actions are reactionary rather than preventive. Monitoring the presence of these viruses in Ae. aegypti where there are high levels of vector density means a better guiding for the vector combat teams. Besides optimizing public resources, this process provides a transmission chain break while the virus is inside the mosquito.

Moreover, according to Pena-Garcia et al..$^{31}$, density of mosquitoes is not a good predictor of dengue cases. Instead, mosquito infection rates can better explain the dengue heterogeneity, helping to predict infections up to six weeks before the onset of cases.

The current Ae. aegypti control program advocates that when a case of Ae. aegypti transmitted disease is identified, control actions should be performed at the probable site of infection, typically the patient's home. However, transmission often occurs in divergent locations, as the mosquito prefers feeding during the daytime ${ }^{32}$, and it is dispersed throughout the city.

The use of molecular methods to detect the presence of these viruses in Ae. aegypti is a powerful tool to perform a fast virological surveillance, allowing the adoption of the most effective prevention measures to deal with these diseases.

\section{CONCLUSION}

The Ae. aegypti infestation rates were comparable for both Central and Marabaixo neighborhoods. However, the study only revealed the presence of the dengue virus in mosquitoes from the Marabaixo neighborhood, showing a low infectivity.

Virological surveillance for Ae. aegypti was important to identify infectivity sites and determine possible routes of transmission, driving the surveillance health team to adopt strategies to act faster in sites where infected mosquitoes were present.

\section{ACKNOWLEDGMENTS}

To Laboratory Vector team for all the support and to collect and identification of mosquitoes.

\section{FUNDING}

This research was funding by FAPEAP (Fundação de Amparo à Pesquisa do Estado do Amapá) and CNPq (Conselho Nacional de Desenvolvimento Científico e Tecnológico), PPSUS N 250.203.0333/2016.

\section{REFERENCES}

1. Lounibos LP. Invasions by insect vectors of human disease. Annu Rev Entomol. 2002;47:233-66.

2. Powell JR, Tabachnick WJ. History of domestication and spread of Aedes aegypti: a review. Mem Inst Oswaldo Cruz. 2013;108 Suppl 1:11-7.

3. Powell JR. Mosquitoes on the move. Science. 2016;354:971-2.

4. Chen LH, Kozarsky PE, Visser LG. What's old is new again: the re-emergence of yellow fever in Brazil and vaccine shortages. Clin Infect Dis. 2019;68:1761-2.

5. Villar L, Dayan GH, Arredondo-Garcia JL, Rivera DM, Cunha $\mathrm{R}$, Deseda C, et al. Efficacy of a tetravalent dengue vaccine in children in Latin America. N Engl J Med. 2015;372:113-23.

6. Pérez Rodríguez AE. Una guía epidemiológica para un vector común y cuatro enfermedades peligrosas (Zika, dengue, chikungunya, fiebre amarilla). Rev Panam Enf Inf. 2018; $1: 33-9$.

7. Brasil. Ministério da Saúde. Secretaria de Vigiliancia em Saúde. Departamento de Vigilância Epidemiológica. Diretrizes nacionais para prevenção e controle de epidemias de dengue. Brasília: Ministério da Saúde; 2009. 
8. Pérez-Pérez J, Sanabria WH, Restrepo C, Rojo R, Henao E, Triana O, et al. Virological surveillance of Aedes (Stegomyia) aegypti and Aedes (Stegomyia) albopictus as support for decision making for dengue control in Medellin. Biomedica. 2017;37:155-66.

9. Monteiro FJ, Carvalho JC, Souto RN. Distribuição da oviposição e dinâmica temporal do Aedes aegypti (Linnaeus) por meio de ovitrampas. EntomoBrasilis. 2014;7:188-92.

10. Cunha AC, Souza EB, Cunha HF, organizadores. Tempo, clima e recursos hídricos: resultados do Projeto REMETAP no Estado do Amapá. Macapá: IEPA; 2010.

11. Instituto Brasileiro de Geografia e Estatística. IBGE divulga as estimativas populacionais dos municípios para 2017. [cited 2020 Jan 14]. Available from: https://agenciadenoticias.ibge. gov.br/agencia-sala-de-imprensa/2013-agencia-de-noticias/ releases/16131-ibge-divulga-as-estimativas-populacionaisdos-municipios-para-2017

12. Natal D, Marucci D. Aparelho de sucção tipo aspirador para captura de mosquitos. Rev Saude Publica. 1984;18:418-20.

13. Azevedo Filho WS, Prates Júnior PH. Técnicas de coleta \& identificação de insetos. 2a ed. Porto Alegre: EDIPUCRS; 2005.

14. Consoli RA, Oliveira RL. Principais mosquitos de importância sanitária no Brasil. Rio de Janeiro: Fiocruz; 1994.

15. Johnson BW, Russell BJ, Lanciotti RS. Serotype-specific detection of dengue viruses in a fourplex real-time reverse transcriptase PCR assay. J Clin Microbiol. 2005;43:4977-83.

16. Michlmayr D, Pak TR, Rahman AH, Amir ED, Kim EY, KimSchulze S, et al. Comprehensive innate immune profiling of chikungunya virus infection in pediatric cases. Mol Syst Biol. 2018;14:e7862.

17. Waggoner JJ, Gresh L, Mohamed-Hadley A, Ballesteros G, Davila MJ, Tellez Y, et al. Single-reaction multiplex reverse transcription PCR for detection of Zika, chikungunya, and dengue viruses. Emerg Infect Dis. 2016;22:1295-7.

18. Ayres M, Ayres Jr. M, Ayres DL, Santos AA. BioEstat: aplicações estatísticas nas áreas das ciências bio-médicas. $5^{\text {a }}$ ed. Belém: Sociedade Civil Mamirauá; 2007.

19. Sivan A, Shriram AN, Sunish IP, Vidhya PT. Host-feeding pattern of Aedes aegypti and Aedes albopictus (Diptera: Culicidae) in heterogeneous landscapes of South Andaman, Andaman and Nicobar Islands, India. Parasitol Res. 2015;114:3539-46.

20. Pérez-Castro R, Castellanos JE, Olano VA, Matiz MI, Jaramillo JF, Vargas SL, et al. Detection of all four dengue serotypes in Aedes aegypti female mosquitoes collected in a rural area in Colombia. Mem Inst Oswaldo Cruz. 2016;111:233-40.
21. Costa-da-Silva AL, Ioshino RS, Petersen V, Lima AF, Cunha MD, Wiley MR, et al. First report of naturally infected Aedes aegypti with chikungunya virus genotype ECSA in the Americas. PLoS Negl Trop Dis. 2017;11:e0005630.

22. Ferreira-de-Brito A, Ribeiro IP, Miranda RM, Fernandes RS, Campos SS, Silva KA, et al. First detection of natural infection of Aedes aegypti with Zika virus in Brazil and throughout South America. Mem Inst Oswaldo Cruz. 2016;111:655-8.

23. Baak-Baak CM, Cigarroa-Toledo N, Pech-May A, Cruz-Escalona GA, Cetina-Trejo RC, Tzuc-Dzul JC, et al. Entomological and virological surveillance for dengue virus in churches in Merida, Mexico. Rev Inst Med Trop Sao Paulo. 2019;61:e9.

24. Eiras AE, Pires SF, Staunton KM, Paixão KS, Resende MC, Silva HA, et al. A high-risk Zika and dengue transmission hub: virus detections in mosquitoes at a Brazilian university campus. Parasit Vectors. 2018;11:359.

25. Cruz LC, Serra OP, Leal-Santos FA, Ribeiro AL, Slhessarenko RD, Santos MA. Natural transovarial transmission of dengue virus 4 in Aedes aegypti from Cuiabá, State of Mato Grosso, Brazil. Rev Soc Bras Med Trop. 2015;48:18-25.

26. Agarwal A, Dash PK, Singh AK, Sharma S, Gopalan N, Rao PV, et al. Evidence of experimental vertical transmission of emerging novel ECSA genotype of Chikungunya virus in Aedes aegypti. PLoS Negl Trop Dis. 2014;8:e2990.

27. Thangamani S, Huang J, Hart CE, Guzman H, Tesh RB. Vertical transmission of Zika virus in Aedes aegypti mosquitoes. Am J Trop Med Hyg. 2016;95:1169-73.

28. Li CX, Guo XX, Deng YQ, Xing D, Sun AJ, Liu QM, et al. Vector competence and transovarial transmission of two Aedes aegypti strains to Zika virus. Emerg Microbes Infect. 2017;6:e23.

29. Silva MM, Rodrigues MS, Paploski IA, Kikuti M, Kasper AM, Cruz JS, et al. Accuracy of dengue reporting by National Surveillance System, Brazil. Emerg Infect Dis. 2016;22:336-9.

30. Brasil. Ministério da Saúde. Secretaria de Vigilância em Saúde. Departamento de Vigilância das Doenças Transmissíveis. Levantamento rápido de índices para Aedes aegypti - LIRAa para vigilância entomológica do Aedes aegypti no Brasil: metodologia para avaliação dos índices de Breteau e Predial e tipo de recipientes. Brasília: Ministério da Saúde; 2013.

31. Peña-Garcia VH, Triana-Chávez O, Mejía-Jaramillo AM, Díaz FJ, Gómez-Palacio A, Arboleda-Sánchez S. Infection rates by dengue virus in mosquitoes and the influence of temperature may be related to different endemicity patterns in three Colombian cities. Int J Environ Res Public Health. 2016;13:1-16. 32. Natal D. Bioecologia do Aedes aegypti. Biologico. 2002;64:205-7. 